\title{
PROPOSTA DE MELHORIA DE PROCESSO UTILIZANDO A QUANTIFICAÇÃO DAS OPERAÇÕES: ESTUDO DE CASO
}

\section{PROPOSAL FOR PROCESS IMPROVEMENT USING QUANTIFICATION OF OPERATIONS: CASE STUDY}

\section{Isabella de Oliveira Dias, Fernando Salem de Oliveira, Andréia Menezes Olivo}

\author{
${ }^{1}$ Universidade do Oeste Paulista - UNOESTE, Faculdade de Engenharia, Presidente \\ Prudente, SP \\ e-mail: isah_dias@live.com; nando_salem@hotmail.com; andreiaolivo@unoeste.br
}

RESUMO - O presente trabalho realizou um projeto de processo que pretendia quantificar as operações e a otimizar a produção de uma empresa que produz doces de amendoim (paçoca). A metodologia adotada foi de abordagem quanti-qualitativa, tendo como procedimento metodológico o estudo de caso. A coleta de dados contou com instrumentos como a observação e, principalmente, a cronoanálise, método proveniente dos estudos de tempos e métodos. No que se refere à análise de resultados, os dados obtidos na cronoanálise foram manipulados matematicamente para a obtenção do tempo padrão. Posteriormente foram relacionados graficamente com o intuito de facilitar sua análise. A partir disso, constatou-se uma possibilidade de aumento da produtividade sem nenhum investimento em infra-estrutura. Outra constatação foi que o real gargalo do processo produtivo encontra-se localizado na etapa de preparação de massa.

Palavras-chave: Processo; Tempos e métodos; Cronoanálise; Paçoca.

Recebido em: 22/03/2018

Revisado em: 23/10/2018

Aprovado em: 13/11/2018
ABSTRACT - The present work carried out a process project that aimed to quantify the operations and to optimize the production of a company that produces peanut sweets (paçoca). The methodology adopted was a quantiqualitative approach, having as a methodological procedure the case study. Data collection included instruments such as observation and, mainly, chronoanalysis, a method derived from time studies and methods. Regarding the analysis of results, the data obtained in the chronoanalysis were manipulated mathematically to obtain the standard time. Later they were graphically related in order to facilitate their analysis. From this, it was possible to increase productivity without any investment in infrastructure. Another finding was that the real bottleneck of the production process is located in the mass preparation stage.

Keywords: Process; Times and methods; Improvements; Peanut candy. 


\section{INTRODUÇÃO}

Com o crescimento da economia e a elevação da competitividade das empresas, a necessidade de reorganização dos fatores produtivos e os métodos de gestão empresarial tornam-se ainda mais necessários para garantir a sobrevivência e a competitividade das empresas, em especial as de pequeno porte. Isso faz com que as empresas precisem adotar novas formas de trabalho em sua produção, com inovações para atender a demanda e a exigência de consumidores. Para sobreviver à concorrência do mercado, as organizações precisam contar com um gerenciamento adequado de seus recursos, dados e procedimentos, e aumentar sua capacidade de resposta às demandas de produto. Para isso, serão indispensáveis formas de adquirir agilidade e flexibilidade dentro da organização, para que se tenha um bom monitoramento do ambiente operacional (ALVARENGA et al., 2005).

O projeto de processo consiste na realização de um mapeamento, que é uma descrição detalhada das atividades executadas. Por meio dele, é possível identificar possibilidades de melhora no processo e oportunidades de redução de custos para o desenvolvimento das atividades e controle de falhas. Além disso, possibilita uma melhor visualização da indústria para a eliminação, simplificação ou mudança dos procedimentos já exercidos (ALMEIDA; CORREIA, 2002).

É possível afirmar que o processo é inerente ao conceito de projeto, o qual é necessário para definir o método que a empresa utilizará para entregar seus produtos aos clientes. Sendo assim, os processos são cíclicos e desenvolvidos em conjunto, envolvendo as pessoas de uma organização. Os produtos ou serviços ofertados aos clientes passam por um processo de transformação, que é representado por uma atividade ou um conjunto de atividades constituídas por itens de entrada (input), que passarão pela transformação e gerarão o item de saída (output), que pode ser tangível ou intangível, ou seja, relacionado, respectivamente, a um bem de consumo ou a um serviço (MELLO; SALGADO, 2005). Em acordo com tais afirmações, Bernegozzi e Goulart (2010, p. 6) compreendem processo produtivo como "toda e qualquer atividade relacionada à elaboração do produto, que a partir da transformação de insumos, matérias-primas, recursos produtivos e humanos, agregam ao produto final".

Chambers, Johnston e Slack (2009) indicam como principal objetivo do projeto de processo a elaboração de um plano que adeque os recursos disponíveis à demanda exigida, assegurando que seu desempenho seja adequado.

Segundo Machado (2006), o amendoim se sobressaía no cenário agrícola brasileiro, por ser uma das principais matérias-primas utilizadas para fabricar óleo comestível. Porém, hoje em dia, o desenvolvimento de soluções tecnológicas voltadas para a colheita mecanizada e para a secagem artificial desse produto levou a uma nova dinâmica para a cadeia do amendoim. Desse modo, sua produção voltou a ser lucrativa, despertando grande interesse na indústria alimentícia, que atende tanto a demanda internacional quanto o mercado interno brasileiro, ambos interessados em um produto de boa qualidade.

$$
\text { É comum que em pequenas e }
$$
médias empresas os processos sejam efetuados de forma não padronizada, ou seja, sua efetivação só é compreensível para quem a realiza. Essa situação se torna mais crítica quando mais de uma pessoa realiza a mesma função, pois, geralmente, cada uma tem suas particularidades e sua maneira própria de executá-la. Logo, se torna imprescindível a elaboração de um sistema de padronização para reduzir esta variabilidade (BONATTO; KOVALESKI, 2013).

$O$ balanceamento de linhas de montagem pode ser definido como a distribuição das tarefas em estações de trabalho, com cada uma utilizando aproxi- 
madamente o mesmo tempo para executar suas atividades, o que tem se apresentado como um problema corriqueiro nas indústrias (CORTIMIGLIA; FOGLIATTO; GERHARDT, 2007).

Este estudo tem como objetivo elaborar um projeto do processo produtivo visando quantificar detalhadamente cada etapa obtendo dados suficientes para propor maneiras organizacionais de otimização da produção em uma empresa do segmento de alimentos na linha de produção de paçocas.

\subsection{Projeto de processo de produção}

De acordo com Lacerda e Manfio (2015) o desenvolvimento de projetos vem tomando o lugar das simples operações rotineiras, devido à necessidade das organizações de crescer e inovar para que assim consiga acompanhar o mercado. Balarine (2010) expõe que o termo projeto pode ser entendido enquanto único e não repetitivo, possuindo duração determinada, organização formal e tendo como foco a efetivação de objetivos já estabelecidos. Burke (1997 apud BALARINE, 2010) define projeto como as atividades a serem executadas em uma sequência lógica, a fim de atingir objetivos pré-determinados, e a Administração de Projetos, é definida como, de maneira mais simples, a forma com que o projeto acontece.

Os projetos possuem atributos,
como exclusividade e finitude, respectivamente devido deterem caminho e tempo próprio, com execução discreta, e um conjunto de objetivos definidos e pouco repetitivos, e, dispor de início e duração determinados. Planejar um projeto compreende um processo predizendo o que será executado, por meio da identificação do trabalho a ser realizado em cada momento. Desse modo, as etapas de um projeto ocorrem de acordo com: o planejamento, o estabelecimento metas, os objetivos, as definições das tarefas e sequenciamentos, baseados nos recursos necessários e disponíveis; o controle, mediando progresso e desempenho; e ações corretivas (BALARINE, 2010).

\subsection{Tempos e métodos}

É comum que em pequenas e médias empresas os processos sejam efetuados de forma não padronizada, ou seja, sua efetivação só é compreensível para quem a realiza. Essa situação se torna mais crítica quando mais de uma pessoa realiza a mesma função, pois, geralmente, cada uma tem suas particularidades e sua maneira própria de executá-la. Logo, se torna imprescindível a elaboração de um sistema de padronização para reduzir esta variabilidade (BONATTO; KOVALESKI, 2013).

Obter informações reais acerca de um processo produtivo traz condições para que se possa realizar modificações e melhorias, tanto de produtividade quanto de qualidade. Para conseguir tais informações faz-se uso dos estudos de tempos e métodos, que proporcionam indicadores confiáveis e essenciais para planejar e controlar os processos (CUSTÓDIO et al., 2012).

A cronoanálise, segundo Custódio et al. (2012), também é proveniente do estudo de tempos e métodos, sendo o fator de maior importância para se definir o tempopadrão, estabelecendo parâmetros tabulados de vários aspectos, e levando a um melhor planejamento e racionalização dos recursos.

Para a realização do estudo de tempos são necessários alguns equipamentos e ferramentas. Seleme (2012) orienta que, geralmente, para a realização de tal estudo, é necessária a utilização de um cronômetro e uma prancheta com uma folha de observações. A folha de observações é um documento que deve conter todas as informações necessárias para o pleno entendimento do processo, onde serão registrados os tempos de execução das atividades e concentrar os elementos necessários para a elaboração do tempo padrão.

Seleme (2012), também destaca que seres humanos têm características diferentes em relação às máquinas, e, devido à está 
situação existem alguns fatores que devem ser considerados, conhecidos como fatores de tolerância, e podem ser classificados em três tipos: tolerância pessoal, tolerância para a fadiga e tolerância de espera.

\subsection{Balanceamento de operações}

Como colocado por Aragão et al. (2008), o estudo do tempo precede a determinação de um balanceamento de capacidades nas diversas etapas do processo. Farnes e Pereira (2006) explicitam que, para obter um melhor aproveitamento dos recursos disponíveis faz-se necessário o balanceamento das etapas do processo para possibilitar o dimensionamento da capacidade de produção, obtendo-se assim, melhores resultados. Além disso, ele auxilia na tomada de decisões quando ocorrem mudanças no processo produtivo. Etapas com tempo ocioso ou sobrecarga demonstram problemas de eficiência, que geram mau aproveitamento da capacidade produtiva e elevam o custo do produto.

O balanceamento de linhas de montagem pode ser definido como a distribuição das tarefas em estações de trabalho, com cada uma utilizando aproximadamente o mesmo tempo para executar suas atividades, o que tem se apresentado como um problema corriqueiro nas indústrias (CORTIMIGLIA; FOGLIATTO; GERHARDT, 2007).

\subsection{Melhorias de processo}

De acordo com Ferreira, Santos e Wanzeler (2010) o cenário globalizado é determinado por grande competitividade e constante inserção de concorrentes, desse modo, as organizações necessitam destacarse no mercado por meio de vantagens competitivas que sustentem e estabilizem seu negócio. Em consequência, as empresas visam melhorar seus processos e controles internos para obter eficácia em seu gerenciamento.

\subsubsection{Amendoim e derivados}

A produção de amendoim no país tem sua concentração maior na região sudeste, principalmente no Estado de São Paulo, responsável por mais de $80 \%$ da produção nacional nas últimas cinco safras. $\mathrm{O}$ amendoim tem sua cadeia produtiva constituída por indústria de insumos, produção agrícola, indústria processadora, distribuição (atacado e varejo) e consumidores finais (MACHADO, 2006).

Segundo Machado (2006), o amendoim se sobressaía no cenário agrícola brasileiro, por ser uma das principais matérias-primas utilizadas para fabricar óleo comestível. Porém, hoje em dia, o desenvolvimento de soluções tecnológicas voltadas para a colheita mecanizada e para a secagem artificial desse produto levou a uma nova dinâmica para a cadeia do amendoim. Desse modo, sua produção voltou a ser lucrativa, despertando grande interesse na indústria alimentícia, que atende tanto a demanda internacional quanto o mercado interno brasileiro, ambos interessados em um produto de boa qualidade.

A paçoca é um doce brasileiro feito à base de amendoim torrado, moído e prensado, sendo um doce típico da região Sudeste, porém conta com uma grande aceitação e popularidade em todo o país. Seu processamento pode ser descrito como uma homogeneização dos ingredientes, tendo o amendoim, já torrado e moído, como base do produto, que posteriormente será moldado e prensado (WARREN, 1999 apud ARAÚJO, 2012).

\section{MÉTODO}

A presente metodologia será apresentada em três tópicos, sendo: métodos, dividido entre a definição de uma abordagem e de seu procedimento; instrumentos de coleta de dados, referente ao levantamento de dados; e, por fim, a forma de análise dos resultados, que corresponderá à maneira como os dados coletados foram manipulados.

O presente trabalho se utilizou da abordagem metodológica quanti-qualitativa, objetivando os benefícios já expostos. O 
procedimento metrológico estudo escolhido, também de acordo com a abordagem utilizada, foi o de estudo de caso, que segundo Dalfovo, Lana e Silveira (2008), consiste em trabalhar as características de um fenômeno e seus desdobramentos. E como principal ferramenta de obtenção de dados quantitativos optou-se pela utilização da cronoanálise, pautado na revisão sobre Tempos e Métodos.

A etapa de observação inicial teve o intuito de entender melhor a dinâmica de trabalho da fábrica, como os processos se inter-relacionam e de que maneira as pessoas realizam as atividades. Esta observação inicial trouxe suporte para que o mapeamento formal do processo fosse mais afirmativo, pois somente com essa vivencia pôde-se entender melhor as particularidades e necessidades do processo produtivo.

O Mapeamento formalizado do processo foi necessário para identificar melhor cada etapa para posteriormente fragmentar as etapas em atividades específicas. Tal mapeamento seguiu o modelo de Seleme (2012), trazendo o fluxograma com a análise do processo já incorporada. Com isso, identificou-se qual o sequenciamento das etapas e entendeu-se a real necessidade de cada uma delas. Também forneceu uma visão mais ampla para a realização de uma mudança de layout.

O processo de coleta de dados se deu por meio da cronoanálise, utilizando um cronômetro. Os dados foram concentrados em uma folha de verificações e posteriormente passados para um software (Excel) somente para facilitar a manipulação.

Manipulando os dados, obteve-se os tempos normais e padrão de cada uma das atividades do processo. Essa informação foi distribuída graficamente, relacionando os tempos padrão a cada etapa do processo, para que possa ser observado visualmente $o$ nível de balanceamento em que o processo produtivo está e identificar os pontos críticos ou gargalos.

Com todas as informações obtidas anteriormente e conhecendo todo o processo, suas características e restrições, foi possível identificar possíveis melhorias de acordo com a realidade da empresa, de modo que seja aprimorado o processo produtivo e utilizado de forma mais eficiente os recursos disponíveis.

\section{RESULTADOS E DISCUSSÕES}

Iniciando os passos metodológicos descritos anteriormente, o primeiro contato com o processo produtivo partiu de um observação das atividades diárias e das dinâmicas de trabalho da empresa, onde, se constatou uma capacidade de infra-estrutura claramente ociosa, com o setor de preparação de massa trabalhando aproximadamente meio período diário e estações de recebimento de produto em grande parte do dia desocupadas. Também foi possível observar que havia uma má utilização da mão de obra disponível. Apesar de serem apenas três colaboradores, as atividades de cada um muitas vezes não era bem definida e a ausência desta organização faz com que se haja perda de tempo e dificultando a obtenção das metas de trabalho e eficiência. No balanço geral do processo observatório também pode-se quantificar uma média produtiva de 17 bateladas por dia, com um escoamento de cerca de $\mathbf{2 8 0}$ quilos de produto diariamente. Neste cenário, em busca de se obter uma a visão de cada uma das etapas do processo produtivo de uma forma mais estruturada, foi elaborado o fluxograma vertical do processo com a descrição das atividades incorporadas, conforme demonstrado na Figura 1.

Após o processo ser segmentado e compreendido, o próximo passo foi realizar a cronoanálise, o local escolhido para partida do estudo foi o setor de preparação da massa de amendoim, que contempla o processo de cozimento, adição de sacarose (açúcar cristalizado) e demais condimentos, homogeneização desta massa até o ponto padrão de textura. Este ponto de textura é padronizado por meio do tempo de 
cozimento e da quantidade de produto a ser produzido.

Os produtos são produzidos e embalado em embalagem unitária com 90 gramas; embalagem com 10 unidades contendo 550 gramas e a embalagem de 40 unidades contendo 2600 gramas no total. De modo geral, o processo de fabricação em si é composto por seis etapas, sendo elas preparação da massa, moldagem, secagem, corte, desenforma e embalagem.

A Figura 2 demonstra os dados obtidos do processo de preparação de massa, no qual foram mapeadas 12 bateladas de produto com tempo de cozimento e batimento cronometrados e também pesagem inicial de cada uma das bateladas.

Na cronoanálise a determinação de tolerâncias e fatores de ritmos são necessários para os cálculos, assim foi realizado uma avaliação qualitativa em relação aos percentuais de tolerância foi considerado $2 \%$ de tolerância pessoal. Pelo fato das atividades serem relativamente simples, de fácil execução e não necessitar grande esforço físico, a tolerância a fadiga foi considerada $5 \%$. Em relação à tolerância de espera, no caso estudado as diversas atividades que compõe o processo produtivo são realizadas por apenas três colaboradores, o que apresenta como vantagem a redução dos tempos ociosos, utilizando assim, apenas $2 \%$ de tolerância de espera. Desta forma, a soma do percentual de cada tipo de tolerância resulta em $9 \%$ que foi utilizado em grande parte do estudo.

A infraestrutura da área de preparação de massa contou com três estações de trabalho, com um lead time (tempo de ciclo) de bateladas de 52 minutos. A partir disso, para determinar a capacidade de produção do setor de preparação de massa, foi quantificado em quanto tempo a preparação de massa consegue liberar uma batelada fazendo uso destas três estações trabalhando simultaneamente, como demonstrado na Figura 3, que quantifica os intervalos entre a liberação de cada batelada de produto em processo. 
Figura 1. Fluxograma vertical.

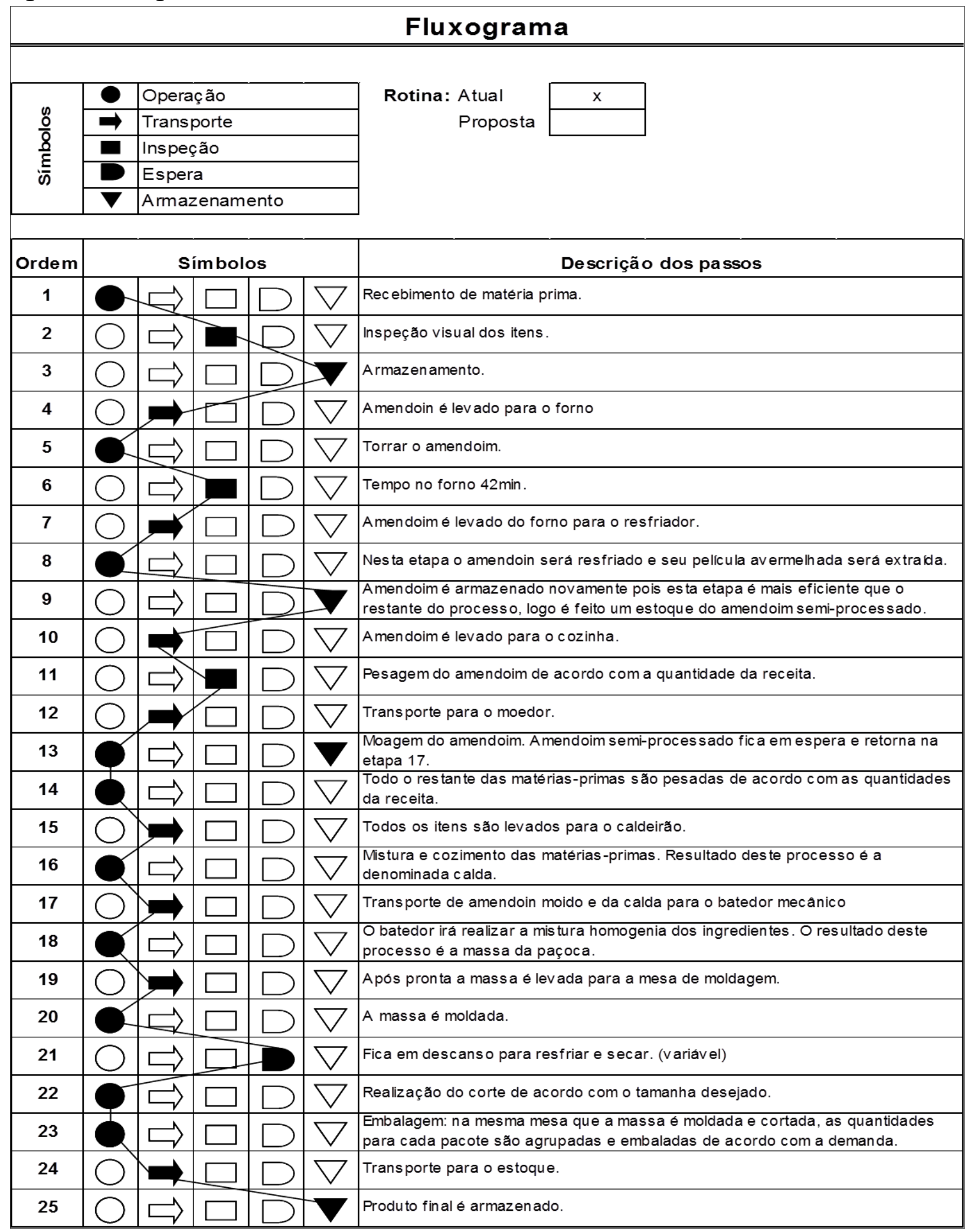

Fonte: Autoria própria. 
Figura 2. Dados coletados o setor de preparação de massa.

\begin{tabular}{|l|c|c|c|c|c|c|}
\hline \multicolumn{7}{|c|}{ Preparação de Massa } \\
\hline & $\begin{array}{l}\text { Pesar } \\
\text { receita }\end{array}$ & $\begin{array}{c}\text { Pesar/moer } \\
\text { amendoi m }\end{array}$ & 10 Fogo & 20 Fogo & $\begin{array}{r}\text { Bater } \\
\text { massa }\end{array}$ & SOMA \\
\hline Amostra 1 & 280 & 227 & 1080 & 960 & 298 & 2845 \\
\hline Amostra 2 & 300 & 140 & 1260 & 960 & 352 & 3012 \\
\hline Amostra 3 & 289 & 149 & 1440 & 960 & 432 & 3270 \\
\hline Amostra 4 & 302 & 150 & 1080 & 960 & 314 & 2806 \\
\hline Amostra 5 & 296 & 143 & 1140 & 960 & 405 & 2944 \\
\hline Amostra 6 & 309 & 156 & 1200 & 960 & 332 & 2957 \\
\hline Amostra 7 & 283 & 160 & 1080 & 960 & 389 & 2872 \\
\hline Amostra 8 & 299 & 137 & 1080 & 960 & 345 & 2821 \\
\hline Amostra 9 & 300 & 163 & 1200 & 960 & 312 & 2935 \\
\hline Amostra 10 & 306 & 184 & 1140 & 960 & 376 & 2966 \\
\hline Amostra 11 & 279 & 149 & 1080 & 960 & 389 & 2857 \\
\hline Amostra 12 & 287 & 135 & 1080 & 960 & 372 & 2834 \\
\hline Tempo Normal (Tn) & 294,17 & 157,75 & 1155,00 & 960,00 & 359,67 & 2926,59 \\
\cline { 2 - 8 } Fator de Tolerância (Ft) & $9 \%$ & $9 \%$ & $5 \%$ & $7 \%$ & $9 \%$ & \\
\hline Tempo Padrão (Tp) & 320,64 & 171,95 & 1212,75 & 1024,32 & 392,04 & 3121,7 \\
\hline Tp em minutos & $05: 20$ & $02: 51$ & $20: 12$ & $17: 04$ & $06: 32$ & $52: 01: 42$ \\
\hline Fonte: Autoria propra. & & & & \\
\hline
\end{tabular}

Fonte: Autoria própria.

Figura 3. Intervalo médio que o setor de preparação de massa libera bateladas.

\begin{tabular}{|c|c|c|c||}
\multicolumn{2}{|c|}{ intervalo médio de saída das bateladas $=$} & $0: 15: 15$ \\
\hline $0: 18: 00$ & $0: 26: 00$ & $0: 25: 00$ & $0: 17: 00$ \\
\hline $0: 13: 00$ & $0: 09: 00$ & $0: 20: 00$ & $0: 16: 00$ \\
\hline $0: 12: 00$ & $0: 18: 00$ & $0: 07: 00$ & $0: 14: 00$ \\
\hline $0: 22: 00$ & $0: 18: 00$ & $0: 21: 00$ & $0: 17: 00$ \\
\hline $0: 06: 00$ & $0: 12: 00$ & $0: 05: 00$ & $0: 09: 00$ \\
\hline $0: 22: 00$ & $0: 23: 00$ & $0: 23: 00$ & $0: 08: 00$ \\
\hline $0: 11: 00$ & $0: 10: 00$ & $0: 14: 00$ & $0: 26: 00$ \\
\hline $0: 13: 00$ & $0: 21: 00$ & $0: 09: 00$ & $0: 10: 00$ \\
\hline $0: 15: 00$ & $0: 15: 00$ & $0: 08: 00$ & $0: 25: 00$ \\
\hline $0: 10: 00$ & $0: 11: 00$ & $0: 29: 00$ & $0: 18: 00$ \\
\hline $0: 16: 00$ & $0: 27: 00$ & $0: 08: 00$ & $0: 05: 00$ \\
\hline $0: 17: 00$ & $0: 10: 00$ & $0: 16: 00$ & $0: 19: 00$ \\
\hline $0: 24: 00$ & $0: 24: 00$ & $0: 17: 00$ & $0: 14: 00$ \\
\hline $0: 14: 00$ & $0: 13: 00$ & $0: 11: 00$ & $0: 16: 00$ \\
\hline $0: 11: 00$ & $0: 20: 00$ & $0: 19: 00$ & $0: 18: 00$ \\
\hline $0: 08: 00$ & $0: 18: 00$ & $0: 10: 00$ & $0: 09: 00$ \\
\hline $0: 19: 00$ & $0: 16: 00$ & $0: 12: 00$ & $0: 19: 00$ \\
\hline $0: 08: 00$ & $0: 24: 00$ & $0: 25: 00$ & $0: 16: 00$ \\
\hline $0: 07: 00$ & $0: 07: 00$ & $0: 06: 00$ & $0: 10: 00$ \\
\hline
\end{tabular}

Fonte: Autoria própria.

Com base nessas informações foi possível definir a capacidade de produção diária do setor de preparação de massa, através da linha de raciocínio descrita na Figura 4.
Figura 4. Capacidade diária de produção do setor de preparação de massa.

\begin{tabular}{|l|r|}
\hline & \multicolumn{2}{|c|}{ minutos } \\
\hline 10 LeadTime: & 52 \\
\hline Após a 1을 batelada a cozinha libera uma a cada: & 15,25 \\
\hline Com 8 horas de trabalho diário: & 480 \\
\hline Após o 1 leadtime restam: & 428 \\
\hline Capacidade de receitas dia: & $\mathbf{2 8 , 0 7}$ \\
\hline
\end{tabular}

Fonte: Autoria própria.

De acordo com a Figura 2, após os primeiros 52 minutos do dia, que é o tempo padrão (Tp) necessário para o setor de preparação de massa liberar a primeira batelada, restam até o final do dia mais 428 minutos de trabalho. Considerando que nesse período o setor de preparação de massa libere uma receita a cada 15 minutos e 15 segundos em média, pode-se concluir que a capacidade produtiva do setor de preparação de massa é de 28 bateladas por dia, com a mesma infraestrutura.

Posteriormente ao setor de preparação de massa vem a etapa de moldagem, que consiste basicamente em distribuir a massa em uma bancada de mármore e moldá-la através de um esquadro. Nessa etapa foram coletas 12 amostras de tempo de realização da atividade, conforme demonstrado na Figura 5.

Figura 5. Dados coletados na moldagem.

\begin{tabular}{|c|c|}
\hline \multicolumn{2}{|l|}{ Moldar } \\
\hline número da amostra & segundos \\
\hline 1 & 251 \\
\hline 2 & 268 \\
\hline 3 & 278 \\
\hline 4 & 280 \\
\hline 5 & 302 \\
\hline 6 & 267 \\
\hline 7 & 302 \\
\hline 8 & 272 \\
\hline 9 & 283 \\
\hline 10 & 268 \\
\hline 11 & 289 \\
\hline 12 & 276 \\
\hline Tempo Normal (Tn) & 278,00 \\
\hline Fator Tolerância (Ft) & $9 \%$ \\
\hline Tempo Padrão (Tp) & 303,02 \\
\hline 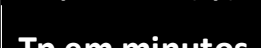 & 5,05 \\
\hline $\mathbf{S}$ & 05:03 \\
\hline Horas decimal/unid. & 0,08 \\
\hline
\end{tabular}

Fonte: Autoria própria. 
A batelada devidamente moldada entrará na etapa de secagem, período de espera no qual a massa deve resfriar e secar em temperatura ambiente. Para esta etapa do processo, vale ressaltar que uma sugestão de melhoria, em busca de otimizar o processo e diminuir o tempo de espera da secagem, seria adequar o local com climatização específica, ou seja, ambientá-lo em busca de temperatura e umidade relativa do ar controladas para que seja possível padronizar os tempos de secagem.

$\mathrm{Na}$ primeira etapa metodológica aplicada foi vivenciado o dia-dia de trabalho da empresa, que indicou a etapa de secagem como a mais crítica do processo, muitas vezes, limitando a capacidade produtiva pelo fato de não haver uma média padrão no tempo de secagem das bateladas, e neste período estas ocupam os postos de recebimento de produto.

Por mais que haja variabilidade no tempo mínimo de secagem da batelada, até que a mesma esteja em condição própria para o manuseio, não existe restrição de tempo máximo que ela fique em descanso, podendo até ser de um dia para o outro e ser manuseada na manhã do dia seguinte.

Esta informação faz com que possa elevar exponencialmente a capacidade de processamento das bateladas nos postos de recebimento disponíveis, que no caso são 17 bancadas. A Figura 6 demonstra como foi calculada a capacidade de processamento de bateladas que as 17 estações proporcionam.

Conclui-se que o total de bancadas tem capacidade de processar 41,41 bateladas por dia, porém sua capacidade de recebimento é de 51 vezes por dia, visto que cada uma das 17 bancadas poderá ser abastecida até três vezes ao dia.
Figura 6. Capacidade de processamento das bancadas.

\begin{tabular}{|c|c|}
\hline $\begin{array}{l}\text { Capacidade de processamento } \\
\text { média do tempo de secagem (horas) }\end{array}$ & $\begin{array}{r}\text { ancadas } \\
2,79 \\
\end{array}$ \\
\hline Fator tolerância(Ft) & $5 \%$ \\
\hline Tempo padrão(Tp) (horas) & 2,93 \\
\hline estações disponíveis & 17 \\
\hline horas disponíveis/dia & 7,13 \\
\hline horas de processamento/dia & 121,21 \\
\hline Capacidade/dia/bancada & 2,44 \\
\hline Capacidade Total/dia & 41,41 \\
\hline
\end{tabular}

Fonte: Autoria própria.

Em relação a etapa de secagem, composta por 17 estações, verifica-se que seu processamento está além da capacidade de produção da primeira etapa, a preparação da massa, que apresenta capacidade de produção de 28 bateladas por dia. Portanto, a etapa de secagem, a qual acreditava-se apresentar um gargalo do processo produtivo devido a sua alta variabilidade, se otimizada, poderá apresentar capacidade superior a etapa de preparação de massa.

A etapa de corte, que consiste em fragmentar a placa de produto em fatias menores, tem duas maneiras diferentes de realização. $O$ corte grande que corresponde a um tipo de produto, sendo ele unitário com 90 gramas, e o corte fino, que irá ser realizado quando for necessário produzir os outros dois produtos finais, que possuem peso de 550 gramas e 2600 gramas.

O corte grande e o fino possuem as mesmas características e são subdivididos em três ou quatro etapas. A primeira é a preparação, que consiste na organização das ferramentas necessárias e a operação de retirar o esquadro de moldagem. Depois são realizados dois cortes, um vertical e outro horizontal, no caso do corte fino é necessário um terceiro corte horizontal. Também foram consideradas algumas paradas extras que fazem parte do processo, como a troca de gabaritos de um corte para o outro e, na maioria das vezes, a limpeza das lâminas, que normalmente acumula resíduos de produto e acaba reduzindo a qualidade do corte. A soma destes fatores resultou em um tempo padrão de realização da atividade, no corte 
grande de 5 minutos e 17 segundos, considerando um fator de tolerância de $9 \%$, e no corte fino considerando o fator tolerância de $9 \%$, calcula-se o tempo padrão de 6 minutos e 44 segundos para a realização da atividade.

Com estes dois tipos de cortes diferentes, a etapa seguinte de desenformar acaba tendo também duas formas diferentes para realizar a atividade de acordo com seu respectivo corte, como demonstrado na Figura 7.

Figura 7. Dados coletados do tempo para desenformar.

\begin{tabular}{|c|c|c|c|c|c|}
\hline \multicolumn{6}{|c|}{ Desenformar } \\
\hline \multicolumn{3}{|c|}{$90 \mathrm{~g}$} & \multicolumn{3}{|c|}{$550 \mathrm{~g} / 2600 \mathrm{~g}$} \\
\hline & tipo & tempo & & tipo & tempo \\
\hline Amostra 1 & grande & 410 & Amostra 1 & fina & 377 \\
\hline Amostra 2 & grande & 449 & Amostra 2 & fina & 368 \\
\hline Amostra 3 & grande & 510 & Amostra 3 & fina & 384 \\
\hline Amostra 4 & grande & 255 & Amostra 4 & fina & 259 \\
\hline Amostra 5 & grande & 370 & Amostra 5 & fina & 352 \\
\hline Amostra 6 & grande & 305 & Amostra 6 & fina & 300 \\
\hline Amostra 7 & grande & 437 & Amostra 7 & fina & 373 \\
\hline Amostra 8 & grande & 332 & Amostra 8 & fina & 389 \\
\hline Amostra 9 & grande & 417 & Amostra 9 & fina & 370 \\
\hline Amostra 10 & grande & 333 & Amostra 10 & fina & 342 \\
\hline \multirow{3}{*}{\multicolumn{2}{|c|}{$\begin{array}{l}\text { Tempo Normal (Tn) } \\
\text { Fator Tolerância (Ft) } \\
\text { Tempo Padrão (Tp) }\end{array}$}} & 381,8 & \multirow{3}{*}{\multicolumn{2}{|c|}{$\begin{array}{l}\text { Tempo Normal (Tn) } \\
\text { Fator Tolerância (Ft) } \\
\text { Tempo Padrão (Tp) }\end{array}$}} & 351,4 \\
\hline & & $9 \%$ & & & $9 \%$ \\
\hline & & 416,162 & & & 383,026 \\
\hline \multicolumn{2}{|c|}{ Tp em minutos } & 06:56 & \multicolumn{2}{|c|}{ Tp em minutos } & $06: 23$ \\
\hline \multicolumn{2}{|c|}{ Horas decimal/unid. } & 0,12 & \multicolumn{2}{|c|}{ Horas decimal/unid. } & 0,11 \\
\hline
\end{tabular}

Fonte: Autoria própria.

Apesar dos tempos padrão das duas variações de desenforma ser próximos, existe uma pequena variação entre eles devido as características de cada uma. Se tratando de cronoanálise e ambiente empresarial, estes pequenos detalhes devem ser considerados e devidamente diferenciados, pois podem fazer grande diferença em planejamentos futuros, conforme as proporções produtivas vão aumentando. Desta forma, de acordo com as amostras coletadas, definiu-se o tempo padrão de 6 minutos e 56 segundos para a realização da atividade de desenformar o corte grande e 6 minutos e 23 segundos para o corte fino.
A partir do momento que a batelada está desenformada o produto está pronto para a embalagem final. Nesta etapa cada um dos três tipos de produto:

A embalagem unitária de 90 gramas é realizado por uma máquina embaladeira, com capacidade superior a necessidade da empresa atualmente. Para mensurar o tempo gasto para a realização deste tipo de embalagem foi necessário considerar não somente a capacidade de produção da máquina, mas sim quanto tempo de trabalho dos três colaboradores são gastos efetivamente para realização da atividade, como demonstrado na Figura 8.

Figura 8. Dados coletados na embalagem de $90 \mathrm{~g}$.

\section{Embalagem para $90 \mathrm{~g}$}

\begin{tabular}{|c|r|}
\hline \multicolumn{2}{|c|}{ Para embalar uma mesa de $\mathbf{1 8 0}$ unid } \\
\hline Tempo gasto/unid. & 1,2 \\
\hline qnt. de colaboradores & 3 \\
\hline Tempo/mesa & 648 \\
\hline hora decimal/mesa & 0,18 \\
\hline minutos/mesa & $\mathbf{1 0 : 4 8}$ \\
\hline
\end{tabular}

Fonte: Autoria própria

Em relação à embalagem de 550 gramas, o corte fino gera 300 unidades de produto e cada pacote conterá 10 unidades. Cada batelada irá gerar 30 unidades de produto final. Para uma melhor quantificação da atividade e também para facilitar os planejamentos futuros, o foco da coleta de dados desta etapa, como na de $90 \mathrm{~g}$, foi mensurar o tempo necessário para embalar uma batelada completa e liberar a estação, como demonstrado na Figura 9.

Foi calculado o tempo padrão de realização da atividade de 20 minutos e 01 segundo, sendo a embalagem de $550 \mathrm{~g}$ o tipo de embalagem que mais irá demandar mão de obra dos colaboradores envolvidos. 
Figura 9. Dados coletados na embalagem de 550g.

Embalagem de $550 \mathrm{~g}$

\begin{tabular}{|c|l|l|l|l|l|l|l|l|l|l|l|l|l}
\hline Tipo & Amostra 1 & Amostra 2 & Amostra 3 & Amostra 4 & Amostra 5 & Amostra 6 & Amostra 7 & Amostra 8 & Amostra 9 & Amostra 10 & Soma & Média Etiquetar Média Total \\
\hline
\end{tabular}

\begin{tabular}{|l|l|l|l|l|l|l|l|l|l|l|l|l|l|l|}
\hline 10 & 26 & 25 & 23 & 26 & 22 & 24 & 25 & 21 & 27 & 23 & 242 & 24,20 & 4 & 28,20 \\
\hline 10 & 36 & 33 & 42 & 44 & 30 & 35 & 33 & 37 & 4 & 35 & 374 & 37,40 & 4 & 41,40 \\
\hline
\end{tabular}

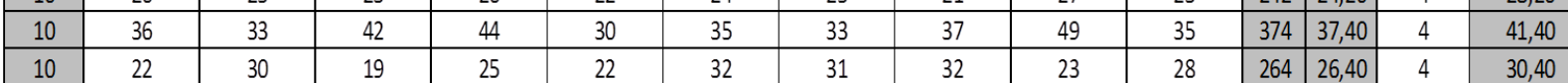

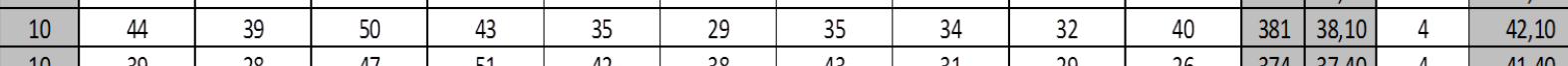

\begin{tabular}{|l|l|l|l|l|l|l|l|l|l|l|l|l|l|l|l|}
\hline 10 & 39 & 28 & 47 & 51 & 42 & 38 & 43 & 31 & 29 & 26 & 374 & 37,40 & 4 & 41,40 \\
\hline 10 & 32 & 25 & 35 & 35 & 24 & 22 & 52 & 33 & 37 & 32 & 327 & 32,70 & 4 & 36,70 \\
\hline
\end{tabular}

\begin{tabular}{|l|l|l|l|l|l|l|l|l|l|l|l|l|l|l|}
\hline 10 & 36 & 24 & 32 & 26 & 34 & 28 & 32 & 32 & 30 & 29 & 303 & 30,30 & 4 & 34,30 \\
\hline 10 & & 26 & 28 & 26 & 45 & 28 & 25 & 44 & 34 & 36 & 341 & 34,10 & 4 & 38,10 \\
\hline
\end{tabular}

\begin{tabular}{|l|l|l|l|l|l|l|l|l|l|l|l|l|l|l|l|l|}
\hline 10 & 49 & 26 & 28 & 26 & 45 & 28 & 25 & 44 & 34 & 36 & 341 & 34,10 & 4 & 38,10 \\
\hline 10 & 24 & 28 & 21 & 27 & 24 & 27 & 33 & 36 & 33 & 42 & 295 & 29,50 & 4 & 33,50 \\
\hline 10 & 49 & 36 & 53 & 41 & 35 & 27 & 34 & 33 & 33 & 31 & 372 & 37,20 & 4 & 41,20 \\
\hline
\end{tabular}

\begin{tabular}{|r|r|c|c|}
\hline Tempo Normal (Tn) & 36,73 & & \multicolumn{2}{|c|}{} \\
\hline Fator Tolerância (Ft) & $9 \%$ & Para embalar uma & 1201,07 \\
\cline { 1 - 1 } Tempo Padrão (Tp) & 40,04 & receita com 30unid.: & $\mathbf{2 0 : 0 1}$ \\
\hline
\end{tabular}

Tp em minutos 00:40

Horas decimal/unid. 0,01

Horas decimal/mesa 0,33

Fonte: Autoria própria.

Figura 10. Dados coletados na embalagem de 2600g.

\begin{tabular}{|c|c|c|c|c|c|c|c|c|c|c|c|}
\hline \multicolumn{12}{|c|}{ Embalagem de $2600 \mathrm{~g}$} \\
\hline Tipo & $\begin{array}{c}\text { Amostra } \\
1\end{array}$ & $\begin{array}{c}\text { Amostra } \\
2\end{array}$ & $\begin{array}{c}\text { Amostra } \\
3\end{array}$ & $\begin{array}{c}\text { Amostra } \\
4\end{array}$ & $\begin{array}{c}\text { Amostra } \\
5\end{array}$ & $\begin{array}{c}\text { Amostra } \\
6\end{array}$ & $\begin{array}{c}\text { Amos tra } \\
7\end{array}$ & Soma & Média & Etiquetar & $\begin{array}{l}\text { Média } \\
\text { Total }\end{array}$ \\
\hline 40 & 125 & 95 & 111 & 134 & 122 & 132 & 121 & 716 & 199,57 & 3 & 122,57 \\
\hline 40 & 92 & 112 & 87 & 58 & 56 & 80 & 56 & 541 & 77,29 & 3 & 80,29 \\
\hline 40 & 81 & 63 & 91 & 81 & 58 & 93 & 54 & 521 & 74,43 & 3 & 77,43 \\
\hline 40 & 87 & 92 & 78 & 79 & 57 & 62 & 75 & 530 & 75,71 & 3 & 79,71 \\
\hline 40 & 64 & 91 & 53 & 76 & 62 & 84 & 69 & 499 & 71,29 & 3 & 74,29 \\
\hline 40 & 59 & 56 & 85 & 65 & 57 & 53 & 54 & 429 & 61,29 & 3 & 64,29 \\
\hline 40 & 76 & 73 & 76 & 62 & 63 & 82 & 63 & 495 & 70,71 & 3 & 72,71 \\
\hline 40 & 101 & 87 & 123 & 106 & 97 & 96 & 108 & 718 & 102,57 & 3 & 105,57 \\
\hline 40 & 114 & 87 & 69 & 82 & 78 & 71 & 54 & 555 & 79,29 & 3 & 82,29 \\
\hline 40 & 63 & 84 & 55 & 65 & 58 & 83 & 87 & 495 & 70,71 & 3 & 73,71 \\
\hline \multicolumn{2}{|c|}{ Tempo Normal (Tn) } & 83,91 & & & & & & & & & \\
\hline \multicolumn{2}{|c|}{ Fator Tolerência (Ft) } & $9 \%$ & \multirow{2}{*}{\multicolumn{2}{|c|}{$\begin{array}{l}\text { Para embalar } \\
\text { receita de } 7,5 \\
\text { unid. Deste }\end{array}$}} & 680,04 & & & & & & \\
\hline \multirow{2}{*}{\multicolumn{2}{|c|}{$\begin{array}{l}\text { Tempo Padrão (Tp) } \\
\text { Tp em minutos }\end{array}$}} & 90,6724286 & & & 11:20 & & & & & & \\
\hline & & 01:30 & & & & & & & & & \\
\hline \multirow{2}{*}{\multicolumn{2}{|c|}{ Horas decimal/unid. }} & 0,03 & & & & & & & & & \\
\hline & & $04: 33$ & & & & & & & & & \\
\hline
\end{tabular}

Fonte: Autoria própria.

O mesmo ocorre com a embalagem de 2600 gramas, também gerando 300 unidades em seu corte, porém cada unidade embalada irá conter 40 unidades, e a média do tempo para etiquetar os pacotes é de 3 segundos, como de acordo com a Figura 10.

A partir dos dados coletados de todas as etapas do processo, para entender melhor as particularidades de cada um dos três produtos, a Figura 11 traça o caminho percorrido de cada um dos produtos e mensura o tempo gasto em cada etapa, como também o lead time de cada um deles desde o início do processo até a embalagem final.
Expondo esta informação graficamente, é possível começar a detectar os eventuais gargalos produtivos e pontos críticos do processo, como demonstrado nas Figuras 12, 13 e 14.

Observando os gráficos fica claro que a etapa que demanda mais tempo de processamento é a secagem, porém esta etapa não requer mão de obra e como comprovado anteriormente, a estrutura presente de 17 estações supri a capacidade que o setor de preparação de massa pode alimentar o processo. Sendo assim, não se caracteriza um gargalo de produção. 
Figura 11. Lead Time de cada produto extratificado.

\begin{tabular}{|c|c|c|c|c|}
\hline \multirow{8}{*}{$90 \mathrm{~g}$} & Etapa & segundos & min. & \\
\hline & Cozinha & 3121,70 & 52,03 & \\
\hline & Moldar & 303,02 & 5,05 & \multirow{3}{*}{$\begin{array}{l}\text { Leadtime } \\
\text { do produto } \\
\text { em horas. }\end{array}$} \\
\hline & Secagem & 10537,85 & 175,63 & \\
\hline & Corte & 317,95 & 5,30 & \\
\hline & Desenformar & 416,162 & 6,94 & 04:15 \\
\hline & Embalagem & 648 & 10,80 & \\
\hline & LeadTime & 15344,68 & 255,74 & \\
\hline \multirow{8}{*}{$550 \mathrm{~g}$} & Etapa & segundos & $\min$. & \\
\hline & Cozinha & 3121,70 & 52,03 & \\
\hline & Moldar & 303,02 & 5,05 & \multirow{3}{*}{$\begin{array}{l}\text { Leadtime } \\
\text { do produto } \\
\text { em horas. }\end{array}$} \\
\hline & Secagem & 10537,85 & 175,63 & \\
\hline & Corte & 404,50 & 6,74 & \\
\hline & Desenformar & 383,026 & 6,38 & $04: 25$ \\
\hline & Embalagem & 1201,07 & 20,02 & \\
\hline & LeadTime & 15951,16 & 265,85 & \\
\hline \multirow{8}{*}{$2600 \mathrm{~g}$} & Etapa & segundos & $\min$. & \\
\hline & Cozinha & 3121,70 & 52,03 & \\
\hline & Moldar & 303,02 & 5,05 & \multirow{3}{*}{$\begin{array}{l}\text { Leadtime } \\
\text { do produto } \\
\text { em horas. }\end{array}$} \\
\hline & Secagem & 10537,85 & 175,63 & \\
\hline & Corte & 404,50 & 6,74 & \\
\hline & Desenformar & 383,026 & 6,38 & 04:17 \\
\hline & Embalagem & 680,04 & 11,33 & \\
\hline & LeadTime & 15430,13 & 257,17 & \\
\hline
\end{tabular}

Fonte: Autoria própria.

Figura 12. Relação gráfica dos produtos com seu tempo de processamento ao decorrer das etapas quando produzido o item de $90 \mathrm{~g}$.

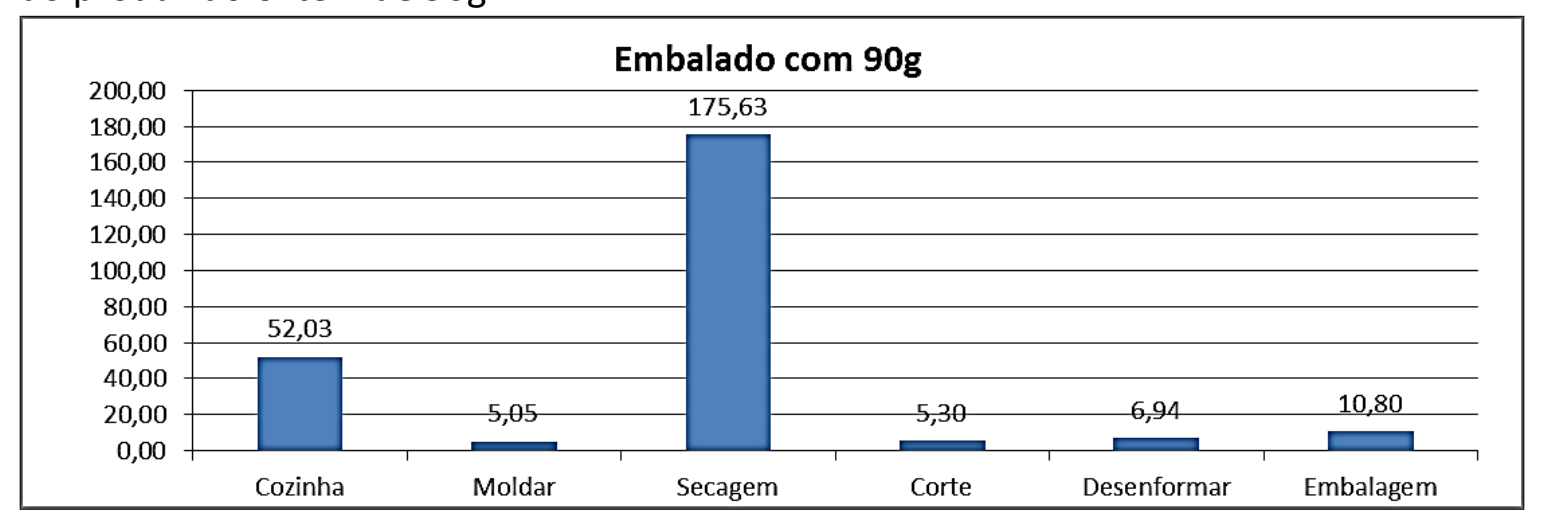

Fonte: Autoria própria. 
Figura 13. Relação gráfica dos produtos com seu tempo de processamento ao decorrer das etapas quando produzido o item de $550 \mathrm{~g}$.

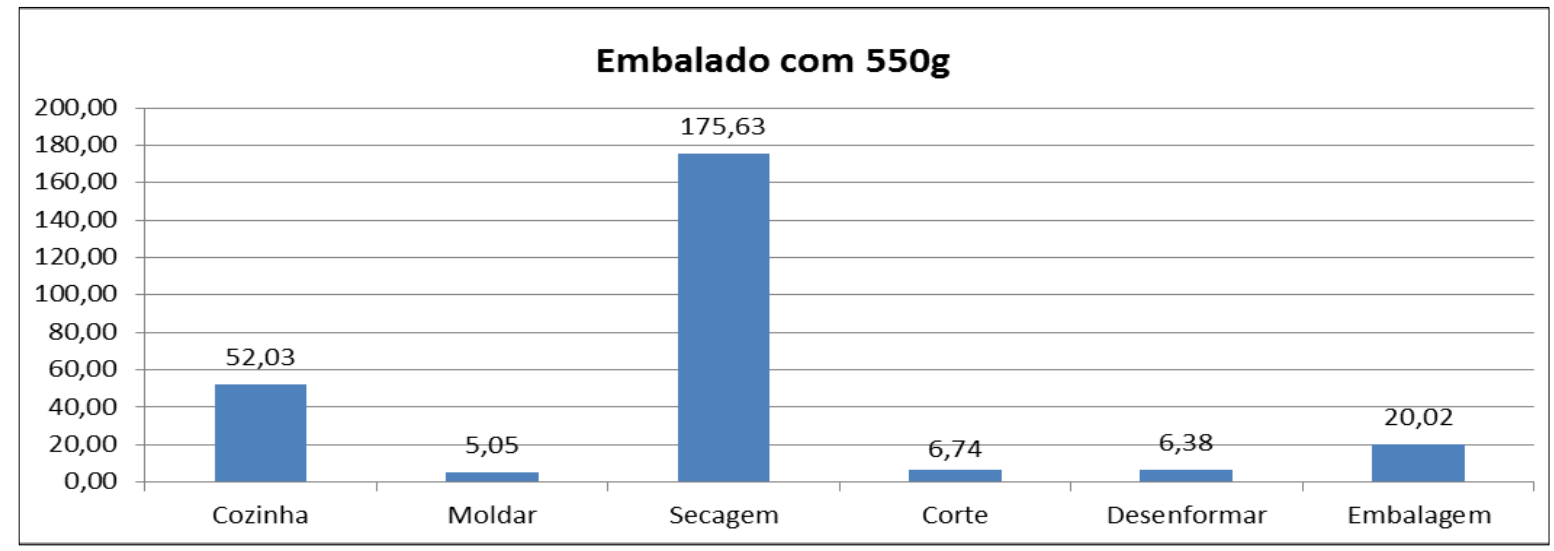

Fonte: Autoria própria.

Figura 14. Relação gráfica dos produtos com seu tempo de processamento ao decorrer das etapas quando produzido o item de $2600 \mathrm{~g}$.

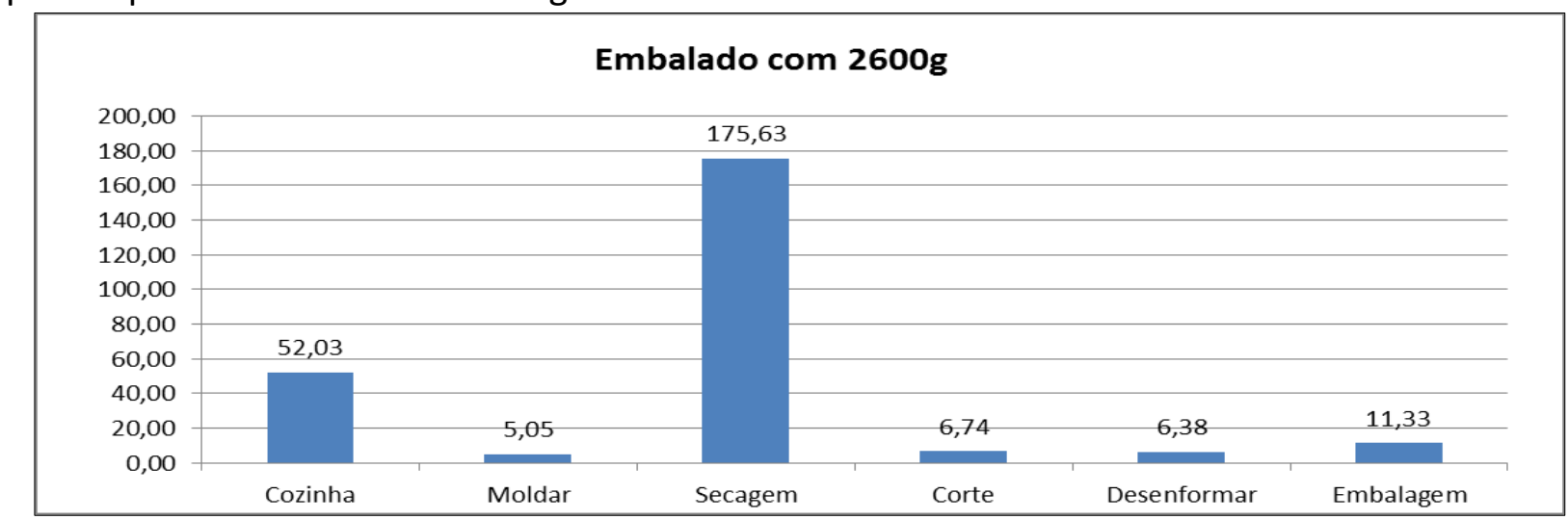

Fonte: Autoria própria.

Em segundo lugar vem o setor de preparação de massa a estrutura atual tem capacidade máxima de produção de 28 bateladas por dia. Para aumentar esta capacidade seria necessário investimentos na infraestrutura fabril e também trabalhar com o quesito demanda, pois atualmente a empresa estudada possui uma capacidade produtiva que está sendo utilizada efetivamente. Logo, parte-se do princípio que o setor de preparação de massa é o principal gargalo e deve focar no que é preciso para que a empresa passe da sua média de produção de 17 bateladas por dia para as 28 bateladas que sua estrutura atual comporta.

\section{CONSIDERAÇÕES FINAIS}

Analisando os parâmetros e resultados obtidos, foi possível obter diretrizes para 0 gerenciamento das atividades e planejamento da produção a curto e médio prazo. Sendo assim, é possível afirmar que uma definição detalhada de todas as etapas do processo produtivo contribui em um melhor controle $e$ aprimoramento das capacidades produtivas de uma empresa de alimentos, inclusive sendo esta de pequeno porte, na qual os métodos produtivos não contam com embasamento técnico ou teórico.

A partir disso, constatou-se uma possibilidade de aumento da produtividade sem nenhum investimento em infraestrutura. Com o levantamento de dados foi possível entender melhor as particularidades de cada um dos três produtos, obtivemos um lead time de 255.74 minutos na embalagem de $90 \mathrm{~g}, 265.85$ minutos na embalagem de $250 \mathrm{~g}$ e 257.17 minutos na embalagem de $2600 \mathrm{~g}$. 
No levantamento da situação inicial do processo foi observado que a empresa produzia em média 17 bateladas de produto por dia. $O$ estudo demonstrou que, com os mesmos equipamentos, é possível produzir 28 bateladas por dia, podendo assim, elevar a produtividade, e, consequentemente, o faturamento da empresa em questão.

Outra constatação foi que a quantificação das etapas de produção favoreceram o processo, demonstrando que uma das queixa do gestor da empresa a respeito de que o setor de secagem seria o principal limitador de sua produtividade, com tempo de 175,63 minutos em todos os três itens, era um equívoco por parte do gestor. Pois, por meio da coleta e análise de dados, concluiu-se que a etapa de secagem tem capacidade de processamento superior, cerca de $50 \%$, em relação ao setor de preparação de massa, ou seja, o real gargalo do processo produtivo encontra-se localizado na etapa de preparação de massa. Esta informação foi de grande importância para definir diretrizes no decorrer do estudo.

Portanto, um estudo quantificado do processo produtivo demonstrou-se eficiente, pois com as informações obtidas através dele foi possível visualizar o processo de maneira ampla contribuindo para um melhor controle a aproveitamento dos recursos disponíveis.

\section{REFERÊNCIAS}

ALMEIDA, D. A.; CORREIA, K. S. A. aplicação da técnica de mapeamento de fluxo de processo no diagnóstico do fluxo de informações da cadeia cliente-fornecedor. In: ENCONTRO NACIONAL DE ENGENHARIA DE PRODUÇÃO, 22., 2002, Curitiba. Anais eletrônicos [...]. Disponível em: http://www.abepro.org.br/biblioteca/ENEGE P2002_TR11_0553.pdf. Acesso em: 04 out. 2017.

ALVARENGA, L. A. et al. Conceitos de lean manufacturing aplicados em uma empresa do ramo alimentício. Jornal Sociedade e
Desenvolvimento da América do Sul, v.1, $\mathrm{n}$. 2, 2005.

ARAGÃO, R. L. et al. Balanceamento de linha de montagem na indústria automotiva: um estudo de caso. In: ENCONTRO NACIONAL DE ENGENHARIA DE PRODUÇÃO, 28., 2008, Rio de Janeiro. Anais eletrônicos [...] Rio de Janeiro: ABEPRO, 2008. Disponível em: http://www.abepro.org.br/biblioteca/enegep 2008_TN_STP_069_496_12064.pdf. Acesso em: 04 out. 2017

ARAÚJO, I. M. S. et al. Elaboração de Doce Tipo Paçoca a Partir do Resíduo da Extração do Óleo de Amêndoa de Castanha-de-Caju. Comunicado Técnico 189, Fortaleza, 2012.

BALARINE, O. F. O. O controle de projetos através dos conceitos de desempenho real (EARNED VALUE), Produção, v. 10, n. 2, p. 3140, maio 2010. https://doi.org/10.1590/S010365132000000200003

BERNEGOZZI, R. P.; GOULART, L. E. T. O uso das ferramentas da qualidade na melhoria de processos produtivos. In: CONFERÊNCIA INTERNACIONAL SOBRE ENGENHARIA INDUSTRIAL E OPERAÇÕES DE GESTÃO, 16., 2010, São Carlos. Anais eletrônicos [...] São Carlos, 2010. Disponível em: http://www.abepro.org.br/biblioteca/enegep 2010_ti_st_113_745_15151.pdf. Acesso em: 04 out. 2017.

BONATTO, F.; KOVALESKI, J. L. Estudo de tempos e métodos para a elaboração de folha de processos no setor de montagem de cadeiras. In: ENCONTRO NACIONAL DE ENGENHARIA DE PRODUÇÃO, 33., 2013, Salvador. Anais eletrônicos [...]. Salvador, $2013 . \quad$ Disponível em: http://www.abepro.org.br/biblioteca/enegep 2013_TN_STP_177_013_22476.pdf. Acesso em: 04 out. 2017

CHAMBERS, S.; JOHNSTON, R. SLACK, N. Projeto de Processo. In: CHAMBERS, S.; JOHNSTON, R. SLACK, N. Administração da 
Produção. 3. ed. São Paulo: Atlas, 2009. p. 87-116.

CORTIMIGLIA, M. N.; FOGLIATTO, F. S.; GERHARDT, M. P. Metodologia para o balanceamento de linhas de montagem multi-modelo em ambientes de customização em massa. Gestão de Produtos, São Carlos, v. 14, n. 2, p. 267-279, maio/ago. 2007. https://doi.org/10.1590/S0104-

\section{X2007000200006}

CUSTÓDIO, M. R. et al. Análise descritiva do estudo de tempos e métodos: uma aplicação no setor de embaladeira de uma indústria têxtil. In: SIMPÓSIO DE EXCELÊNCIA EM GESTÃO E TECNOLOGIA, 9., 2012, Rio de Janeiro. Anais eletrônicos [...]. Rio de Janeiro: SEGET, 2012. Disponível em: http://www.aedb.br/seget/arquivos/artigos1 2/22316596.pdf. Acesso em: 04 out. 2017.

DALFOVO, M. S.; LANA, R. A.; SILVEIRA, A. Métodos quantitativos e qualitativos: um resgate teórico. Revista Interdisciplinar Científica Aplicada, Blumenau, v. 2, n. 4, p. 01-13, 2008.

ESCRIVÃO FILHO, E.; TERENCE, A. C. F. Abordagem quantitativa, qualitativa e a utilização da pesquisa-ação nos estudos organizacionais. In: ENCONTRO NACIONAL DE ENGENHARIA DE PRODUÇÃO, 26.,, out. 2006, Fortaleza.

http://www.abepro.org.br/biblioteca/enegep 2006 tr540368 8017.pdf. Acesso em: 4 out. 2017.

FARNES, V. C. F.; PEREIRA, N. A. Balanceamento de linha de montagem com o uso de heurística e simulação: estudo de caso na linha branca. In: SIMPÓSIO DE ENGENHARIA DE PRODUÇÃO, 13., 2006, Bauru. Anais eletrônicos [...]. Bauru: SIMPEP, 2006. Disponível em: http://www.simpep.feb.unesp.br/anais/anais _13/artigos/1000.pdf. Acesso em: 04 out. 2017.
FERREIRA, L. M. L.; SANTOS, Y. B. I.; WANZELER, M. S. Padronização de processos em uma empresa do setor moveleiro: um estudo de caso. In: ENCONTRO NACIONAL DE ENGENHARIA DE PRODUÇÃO,30., 2010, São Carlos. Disponível em: http://www.abepro.org.br/biblioteca/enegep 2010 tn stp 113745 16460.pdf. Aceso em: 4 out. 2017.

LACERDA, D. P.; MANFIO, N. M. Definição do escopo em projetos de desenvolvimento de produtos alimentícios: uma proposta de método. Gestão e Produção, São Carlos, abr. 2015.

MACHADO, J. G. C. F. Análise das estratégias de marketing das indústrias de processamento de amendoim da região de Tupã-SP. In: CONGRESSO DA SOCIEDADE BRASILEIRA DE ECONOMIA RURAL, 46., jul. 2006, Fortaleza. Disponivel em: http://www.sober.org.br/palestra/5/853.pdf. Acesso em: 4 out. 2018.

MELLO, C. H. P.; SALGADO, E. G. Mapeamento dos processos em serviços: estudo de caso em duas pequenas empresas da área de saúde. In: ENCONTRO NACIONAL DE ENGENHARIA DE PRODUÇÃO, 25., 2005, Porto Alegre. Anais eletrônicos [...]. Porto Alegre: ENEGEP, 2005. Disponível em: ww.abepro.org.brbibliotecaENEGEP2005_En egep0207_0556.pdf. Acesso em: 04 out. 2017.

SELEME, R. Métodos e Tempos: racionalizando a produção de bens de serviço. Curitiba: Intersaberes, 2012. 